\title{
Práticas tecnológicas na educação inclusiva durante a pandemia do COVID-19
}

\author{
Technological practices in inclusive education during the COVID-19 \\ pandemic
}

Maitê Vitorino

Especialista em Inovação na Educação.

Universidade do Vale do Itajaí - UNIVALI.

Itajaí, Santa Catarina - Brasil. maitevitorino2@gmail.com

Bruna Carolina de Lima Siqueira dos Santos Mestre em Educação Universidade do Vale do Itajaí - UNIVALI. Itajaí, Santa Catarina - Brasil. bruna_siqueiras@hotmail.com

Verônica Gesser

Doutora em Educação

Universidade do Vale do Itajaí - UNIVALI.

Itajaí, Santa Catarina - Brasil. gesserv@univali.br

Resumo: O contexto marcado pela pandemia do COVID-19, trouxe diversos desafios, no campo da educação. Escolas precisaram se reorganizar, visando garantir o atendimento aos alunos, nesse contexto, a tecnologia foi encontrada como uma solução para intermediar esse processo. Estudos que abordam essa nova perspectiva já podem ser encontrados, contudo, no presente estudo, chamamos atenção para um ângulo por vezes tangenciado, que é o objeto desta pesquisa: multiplicidades, em especial o atendimento aos alunos com deficiência. O que nos instiga a questionar: Quais metodologias e recursos tecnológicos estão sendo adotados pelos professores da educação inclusiva, para garantir o atendimento educacional. O estudo caracteriza-se como exploratório e qualitativo. A coleta de dados foi realizada através da técnica de grupo focal. Os dados, coletados foram analisados por meio da metodologia da Análise Textual Discursiva - ATD. Os resultados da pesquisa, apontam desafios, potencialidades, estratégias e desafios pessoais.

Palavras chave: deficiência; inclusão; inovação educacional; tecnologias.

Abstract: The context marked by the COVID-19 pandemic, brought several challenges, in the field of education. Schools needed to reorganize themselves, to guarantee the service to students, in this context, technology was found as a solution to mediate this relationship. Studies that address this new perspective can already be found, however, at present, we draw attention to an angle that is sometimes tangential, which is the object of this research: the multiplicities, especially in the care of students with disabilities. Which prompts us to question: What methodologies and technological resources are being adopted by inclusive education teachers to ensure educational assistance. The study is characterized as exploratory and qualitative. Data collection was per formed using the focus group technique. The collected data were analyzed using the Discursive Textual Analysis - ATD methodology. The survey results point out challenges, potentials, strategies and personal challenges.

Key-words: deficiency; inclusion; educational innovation; technologies.

Cite como

(ABNT NBR 6023:2018)

VITORINO, Maitê; SANTOS, Bruna Carolina de Lima Siqueira; GESSER, Verônica. Práticas tecnológicas na educação inclusiva durante a pandemia do COVID-19. Dialogia, São Paulo, n. 39, p. 1-14, e20616, set./dez. 2021. Disponível em: https://doi.org/10.5585/39.2021.20616.

American Psychological Association (APA)

Vitorino M., Santos, B. C. de. S., \& Gesser, V. (2021, set./dez.) Práticas tecnológicas na educação inclusiva durante a pandemia do COVID-19. Dialogia, São Paulo, 39, p. 1-14, e20616. https://doi.org/10.5585/39.2021.20616. 
Introdução

A sociedade contemporânea busca se pautar em princípios democráticos para vivência, podemos perceber movimentos cada vez mais amplos no que se refere ao espaço da multiplicidade, nessa perspectiva, abordamos diálogos sobre igualdade de condições e reinvindicação do direito e respeito as diferenças.

O presente estudo se desenvolveu concomitantemente ao contexto histórico marcado pela crise sanitária apresentada pela COVID-19, que não apenas apresentou novos desafios, como descortinou dificuldades antigas decorrentes por vezes da ausência ou ineficiência de políticas públicas.

Nesse complexo, ao iniciarmos com uma breve partida sobre as diversidades e políticas públicas, apresentamos o recorte que nos fixamos a investigar neste estudo, a saber, chamamos olhares para o contexto escolar e em especial neste contexto, ao atendimento de alunos com deficiência. Sabe-se que estes possuem direitos assegurados por lei e necessitam ter a garantia de que estes direitos sejam efetivamente cumpridos, como por exemplo, neste estudo tratado, o acesso pleno com condições de equidade no sistema de ensino que assegurem o desenvolvimento integral.

Nesse sentido, segundo a Lei Brasileira de Inclusão da Pessoa com deficiência, deve-se trazer uma perspectiva inclusiva e um atendimento diferenciado ao sujeito em questão, assim, assegura que o sistema educacional seja inclusivo em todos os aspectos e níveis de aprendizagem ao longo da vida, oferecendo as possibilidades para que esta pessoa possa alcançar o máximo de seu desenvolvimento possível, considerando seus talentos, habilidades físicas, sensoriais, intelectuais e sociais, respeitando suas características, interesses e necessidades de aprendizagem (BRASIL, 2015).

Compreende-se que, o campo educacional sempre foi marcado por desafios diversos e neste estudo ao destacarmos os que se referem a educação de alunos com deficiência, corroboramos com Nunes, Saia e Tavares (2015) ao afirmarem que a inclusão é um caminho para a humanização, embora possamos concordar que esta modalidade de atendimento educacional tem alcançado alguns avanços e olhares mais sensíveis, sabe-se que ainda há um longo caminho a se percorrer.

O momento atual, revela ainda mais os desafios, uma vez que, podemos perceber um grande esforço das secretarias de educação para atender aos alunos e garantir o cumprimento dos currículos, para tanto, o território nacional, encontrou alternativa na transição das aulas presenciais para aulas em ambientes remotos, fazendo uso de tecnologias de informação. Contudo, mais uma vez, observa-se ainda ser debilitado o atendimento também nesse formato aos alunos com 
deficiência, considerando que estes também precisam e possuem o direito a serem atendidos, de maneira que tenham asseguradas que seus processos de desenvolvimento.

Com relação ao uso das tecnologias, podemos perceber que estas favorecem, compensam, potencializam e/ou auxiliam, tanto na escola como em outros espaços, sendo entendidas como um tipo de mediação instrumental, ou seja, objetos feitos com um fim específico que, no contexto escolar especificamente, rompem barreiras físicas no acesso ao aprendizado (GALVÃO-FILHO, 2013). Ainda conforme o autor, com a equiparação de oportunidades viabilizadas, propicia aos alunos, condições maiores para superar barreiras como um pleno aprendizado e eliminação dos preconceitos, "como consequência do respeito conquistado com a convivência, aumentando sua autoestima, porque passa a poder explicitar melhor seu potencial e seus pensamentos." (GALVÃOFILHO, 2013, p.19).

Partindo das contribuições do uso das tecnologias, no que concerne aos alunos com deficiência se faz necessário, um olhar ainda mais sensível para garantir que nenhuma criança independente de suas especificidades, seja prejudicada ou tenham seus direitos negligenciados. Nesse contexto, temos como hipótese nesta pesquisa que: as ferramentas tecnológicas podem ser potentes aliadas neste processo, deste que pensadas de forma diferenciada e bem direcionadas. Assim, destaca-se a relevância desta pesquisa, que objetiva: Compreender quais metodologias e recursos tecnológicos estão sendo adotados pelos professores da educação inclusiva, para garantir o atendimento educacional.

Para melhor compreensão do estudo, o texto foi estruturado da seguinte forma: Introdução; apresentando o recorte de pesquisa, relevância, questão norteadora, objetivo e principais autores que fundamentam as compreensões. Na sequência, na seção - COVID-19 e os Desafios para a Educação; apresentamos de forma mais aprofundada o contexto no qual esta pesquisa se insere, seguido pela seção - Pessoa com deficiência e a relação entre Tecnologia e Educação; em que fundamentamos nossa discussão a respeito do recorte selecionado, abordando a partir da perspectiva do atendimento ao aluno com deficiência a relação entre tecnologias e educação. Posteriormente na seção - Metodologia; discorremos sobre a natureza, abordagem e percurso metodológico que permitiram a coleta dos dados e suas respectivas analises aqui apresentadas. Nesse sentido, na seção posterior - Análise e Discussão dos Resultados; estão dispostas quatro categorias, nas quais apresentamos e análisamos os dados coletados a luz dos referenciais que embasam o estudo, finalizamos com as considerações finais, amarrando as discussões e destacando os achados. 


\section{COVID-19 e os desafios para a educação}

Reconhecido pela Organização Mundial da Saúde como uma pandemia no início do ano de 2020, o novo coronavírus, SARS-Cov-2, ou COVID-19, foi identificado no final de 2019, na China, com um alto potencial de transmissão, se apresentou como um dos problemas de saúde mais graves por causar inicialmente grande letalidade em idosos, pessoas com doenças crônicas, respiratórias (HELIÓTERIO, et al., 2020), no decorrer da pandemia, estão sendo afetados os mais diversos grupos de pessoas, em muitos casos, não apenas aqueles que se enquadram nos nominados grupos de risco.

A pandemia exigiu que governos de todo o mundo tomassem diversas medidas de contenção, este fato teve enorme impacto social, sanitário, econômico e educacional, por impor a necessidade de grandes reorganizações de forma emergencial. Desde então, a busca por ações reinventivas tem sido constante, em todos os setores sociais, incluso nestes o escolar.

As escolas passaram a adotar ainda mais o uso de tecnologias da informação, seja modalidade de ensino remoto, que são aulas ao vivo, Educação a Distância (EAD) que se referem as aulas gravadas flexíveis ao tempo e disponibilidade do aluno ou já em 2021 o modelo híbrido que se refere à alternância de aulas online e aulas presenciais (vale ressaltar que o modelo híbrido na maioria das escolas não se estende aos alunos com deficiência).

O uso das tecnologias para além do atendimento dentro do espaço escolar, possui respaldo legal no artigo 80 da Lei no 9.394, (p.50) que diz respeito a Lei de Diretrizes e Bases da Educação Brasileira - LDB, que estabelece: "Poder Público - incentivará o desenvolvimento e a veiculação de programas de ensino a distância, em todos os níveis e modalidades de ensino, e de educação continuada.".

Embora esta modalidade de ensino seja amparada por lei para todos os níveis, não era um modelo comumente utilizado pela educação básica. Por ter se tornado a única alternativa viável em meio a pandemia, inicialmente gerou grande desconforto, por parte grande da comunidade escolar. Essa mudança implicou em novos desafios e o encontro de tecnologias voltadas inicialmente para outros fins, agora redirecionadas também a fins educacionais como Facebook, Instagram, Whats App, atreladas a outras que já eram pretensamente destinadas, contudo, pouco utilizadas, bem como plataformas e serviços como o classroom, zoom, meet dentre outros, que passaram a ser intensamente utilizadas pelas escolas, na tentativa de readaptação ao novo cenário, exigindo de professores por exemplo, a adaptação dos planos de aula, focando seus saberes em novas estratégias, montando todo um sistema de educação em novos ambientes, como coloca Rosa (2020, p. 5) adaptando os espaços de suas residências, em salas de aula improvisadas. 
Entretanto, dentre essas mudanças houve um grande conflito, no qual educadores perceberam que o ensino nesta modalidade, possui diversas limitações e exigências, como conhecimento prévio de ferramentas que podem ser utilizadas, segundo Leal (2020, p.42), a exigência de saberes sobre quais metodologias e didáticas podem ser acessíveis para facilitar e contribuir com o ensino-aprendizagem, perfis socioeconômicos que enfrentam problemas como a falta de recursos adequados, como computador ou acesso a internet e como fazer com que esse modelo de educação seja acessível aos alunos com deficiência.

\section{Pessoa com deficiência e a relação entre tecnologia e educação}

A Lei Brasileira de Inclusão da Pessoa com Deficiência - LBI, entende que pessoa com deficiência é aquela que tem impedimento de longo prazo de natureza física, mental, intelectual ou sensorial, que em interação com uma ou mais barreiras, pode obstruir sua participação plena e efetiva na sociedade em igualdade de condições com as demais pessoas, e busca até hoje trazer uma perspectiva inclusiva e um entendimento diferente destas pessoas (BRASIL, 2015). A LBI se aproxima do campo da educação, ao incluí-la como um dos principais direitos pertencentes as pessoas com deficiência.

Nos últimos anos, o campo da inclusão escolar trouxe diversas discussões acerca do que é importante para o exercício da convivência social a fim de lidar com as diferenças e com objetivo de que todos tenham uma educação de qualidade. Nota-se que preocupações mais específicas e avanços diante dessa temática em nosso país, é algo ainda recente e mesmo que os objetivos propostos pela lei Brasileira de Inclusão da Pessoa com Deficiência estejam bem estabelecidos para que as escolas de modo geral se tornem ambientes inclusivos em suas práticas e estruturas, corroboramos com Monteiro (2020, p.40), que a burocracia existente principalmente na rede pública de ensino, dificulta por vezes a busca por recursos para adequação de materiais ou estratégias para atender às possíveis necessidades pedagógicas emergentes no ambiente escolar

Acordamos que, uma escola ética, não se ocupa apenas em cumprir determinações legais pelo princípio da obrigatoriedade, vai além, e interpreta o princípio presente na Constituição, artigo 2006, inciso 1: "A igualdade de condições para o acesso e permanência na escola", não como igualdade de tratamento ou estratégias, uma vez que isso seria perceber as crianças como homogenias, desconsiderando as diferenças e diversidades existentes. Nesse sentido, Mantoan e Prieto (2006, p. 16, grifos dos pesquisadores), dissertam que, 


\begin{abstract}
A inclusão escolar está articulada a movimentos sociais mais amplos, que exigem maior igualdade e mecanismos mais equitativos no acesso a bens e serviços. Ligada a sociedades democráticas que estão pautadas no mérito individual e na igualdade de oportunidades, a inclusão propõe a desigualdade de oportunidades, a inclusão propõe a desigualdade de tratamento como forma de restituir uma igualdade que foi rompida por formas segregadoras de ensino especial e regular.
\end{abstract}

Sobre essa busca, Alves, Pereira e Viana (2017), discorrem que a educação inclusiva vem sendo fortalecida desde a década de 1970, através de um movimento que buscava estruturar a escola para que os alunos com deficiência fossem inclusos, na qual, os educadores entraram em uma incessante busca para encontrar diferentes práticas, que ao longo dos anos passaram a ser tecnológicas, refletindo na interação do processo de ensino e aprendizagem dos sujeitos em questão, sendo consideradas como possíveis facilitadoras e potencializadoras da autonomia dos referidos sujeitos.

Nesse sentido, ao abordarmos tecnologias, o fazemos por compreendermos que, tecnologia é um produto da engenharia, que envolve um conjunto de instrumentos, métodos e técnicas que visam a solução de um problema, porém, conforme Lopes, Freitas e Freitas (2017), neste campo, toda tecnologia deve ser vista como um processo de facilitação e não como uma solução e precisa transformar os atores envolvidos, sendo capaz de considerar a interação com a capacidade de produzir conhecimentos a respeito desse processo de aprendizagem.

\title{
Metodologia
}

Para o desenvolvimento do presente estudo, adotamos uma natureza exploratória com abordagem qualitativa. A pesquisa contou com a participação de 3 professores de instituições distintas que atuam na Educação Inclusiva na rede básica de educação de um Município de Santa Catarina. Utilizamos como critério de inclusão, aqueles professores que já atuam na função por um período mínimo de dois anos, uma vez que nosso interesse se dava em ouvir suas experiências a partir das vivências neste cotidiano específico e no contexto atual.

Os participantes da pesquisa foram designados por meio de sorteio realizado pelo coordenador responsável da Educação Especial na rede em que atuam. Após contatados e convidados individualmente, todos aceitaram participar da pesquisa. Quanto as características gerais do grupo, podemos destacar que estes possuem experiência na educação inclusiva entre 7 e 14 anos, graduados em pedagogia com especialização nas seguintes áreas: Análise do Comportamento Aplicada - ABA, docência na educação, educação especial, gestão escolar, neuroaprendizagem, neuropsicopedagogia, educação inclusiva, psicopedagogia e saúde mental. 
Para a coleta de dados foi utilizado como instrumento, a técnica de grupo focal, de acordo com Gatti (2005, p.11), "O trabalho com grupos focais permite compreender processos de construção da realidade por determinados grupos sociais, compreender práticas cotidianas, ações e reações a fatos e eventos [...].".

Destaca-se que, considerando o contexto em que a pesquisa se realizou, os encontros para realização do grupo focal foram realizados de forma on-line. Cada participante recebeu um link para acesso ao encontro que ocorreu por meio da plataforma Blackboard. A condução dos diálogos nos encontros se deu mediante a exposição de imagens "charges", que abordavam o contexto atual, na sequência, os participantes foram convidados a colocarem seus pontos de vista sobre cada uma delas. Após as exposições das imagens, foi realizada uma entrevista semiestruturada com o grupo. A entrevista semiestruturada, conta com um roteiro de perguntas abertas, conforme as respostas são fornecidas outros questionamentos são elaborados quando necessários para melhor compreensão.

Para análise dos dados coletados, adotamos a metodologia da Análise Textual Discursiva ATD, proposta por Moraes e Galiazzi (2011), que consiste em quatro momentos interligados, conforme ilustrado na Figura 2 abaixo:

Figura 2 - Ciclos do Processo em ATD

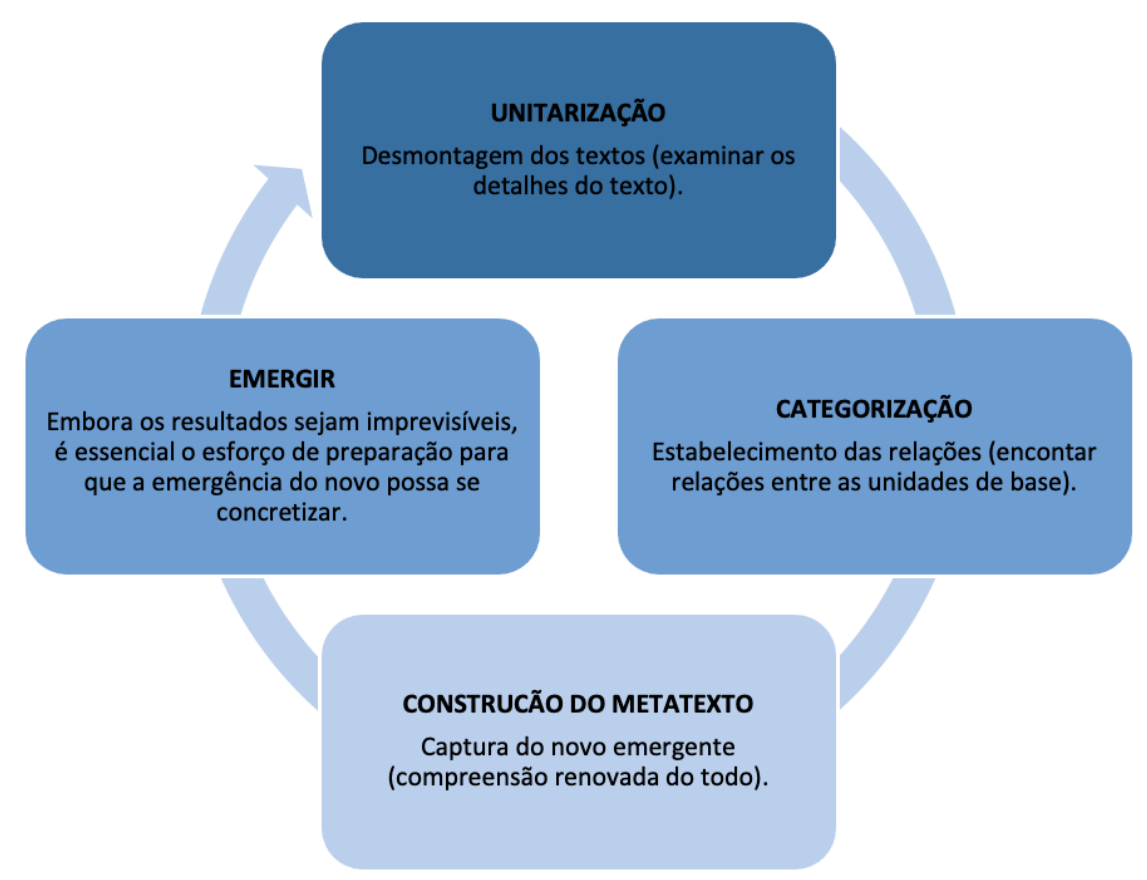

Fonte: SANTOS (2018). Dissertação de mestrado. 
A ATD é um movimento cíclico, que se refere a um processo contínuo de retomada, à medida que os dados são coletados, as relações vão sendo estabelecidas, a metodologia pressupõe o esforço do pesquisador para alcançar os objetivos traçados e um esforço maior para encontrar o novo emergente, ou seja aquilo que não estava previsto, mas que manifestou-se no percurso da pesquisa. Nessa perspectiva, organizamos as análises em categorias que conversam entre si. Destaca-se que a pesquisa foi submetida e aprovada pelo comitê de ética em pesquisas que envolvem seres humanos, conforme parecer de aprovação número: 4.430.504.

\section{Análise e discussão dos resultados}

Buscando compreender quais as metodologias e recursos tecnológicos, estão sendo adotados pelos professores da educação inclusiva para garantir o atendimento educacional, especialmente durante o tempo de pandemia do novo coronavírus a partir das referências existentes sobre o assunto e através da perspectiva dos dados resultantes da entrevista com os professores, as narrativas foram categorizadas para melhor análise, resultando em quatro: 01- Desafios da educação inclusiva durante a pandemia; 02- Potencialidades; 03- Estratégias e 04- Desafios pessoais, esta última se caracteriza como o novo emergente, sendo o encontro no meio do percurso.

Buscando preservar a identidade dos participantes, como um dos princípios de ética na pesquisa, as narrativas se apresentam da seguinte forma, P1, P2 e P3, que se referem a P - Professor seguido do número de identificação.

\section{Categoria 01: desafios da educação inclusiva}

Sabe-se que o atendimento educacional especializado histórica, cultural e socialmente, apresenta desafios diversos. No entanto, o contexto atual e suas demandas resultou na intensificação destes desafios. A este respeito, quando questionados sobre os maiores desafios que os professores têm encontrado para atender e garantir um ensino de qualidade aos alunos com deficiência, neste período, responderam:

[...] Cada criança tem uma necessidade específica tanto que precisamos escrever um plano individual para cada criança... Então como é que vou atender de forma qualitativa, se temos esse tanto de crianças? Esse ano eu iniciei o atendimento individual, de segunda a sexta, é como se a gente levasse escola para casa $[\ldots](\mathrm{P} 1)$.

[...] Enquanto profissional de educação especial que eu posso falar [...] nós que trabalhamos com educação especial trabalhamos diretamente com olhar no olho dos alunos, então nesse momento, a gente não tá conseguindo absolutamente nada, é, as pessoas "ah, liga o vídeo" 
mas não é a mesma coisa, né? Um aluno com deficiência tem muito mais dificuldade de se concentrar, de entender o que a gente fala... Imagina tu numa câmera tentando explicar paro aluno fazer, é irreal [...] (P3).

O impacto do fechamento das escolas como efeito da pandemia do COVID-19, se torna ainda mais visível a partir do momento que ouvimos essas narrativas, uma vez que o ensino remoto implica em condições mínimas para que as aulas sejam de fato efetivadas, tanto no que se relaciona ao trabalho dos professores, quanto no que se refere ao aprendizado dos alunos.

A educação a distância, que tem sido utilizada como referência para o desenvolvimento de aulas em ambientes remotos, por exemplo, conforme sua legislação própria, pressupõe a necessidade de uma equipe qualificada, desde a produção de materiais até o trabalho docente, no qual o foco é a aprendizagem do aluno. O contexto descortina a falta de investimento que priorizem o melhor preparo de professores para o conhecimento de manuseio de tecnologias educacionais que atendam as especificidades de todos os alunos, para que não se fortaleça a ideia segregadora de uma escola apartada dos demais alunos ditos "normais", mas, que inclusos no mesmo ambiente, presencial ou remoto, os alunos com deficiência sejam amparados por estratégias diferenciadas que lhes garantam a inclusão,

[...] com as diferentes tecnologias educacionais e as diferentes estratégias pedagógicas, que de fato buscaria responder às suas dificuldades e necessidades especificas para o aprendizado, a cada momento e de forma individual, da mesma forma que todos os demais estudantes também necessitam na escola inclusiva. (GALVÃO-FILHO, 2013, p.1).

O que vivenciamos atualmente é um atendimento em caráter emergencial, ou seja, ainda não possui suas próprias legislações, apenas orientações que devem ser seguidas. O professor como mediador de conhecimento, acaba por ter suas funções limitadas e tenta utilizar os mais variados tipos de recursos na tentativa de acerto (TAMAYO; SILVA, 2020).

Este fato, tem gerado a comunidade escolar desconforto, uma vez inseridos em um contexto de incertezas. Desse modo, entende-se que é compreensível a fala dos professores, uma vez que é de comum acordo que há uma grande preocupação pedagógica em adaptar o conteúdo ao ensino virtual sem preparo prévio, considerando que as aulas ocorrem na maioria das vezes em um mesmo horário com a turma, o que exige que os conteúdos sejam mediados de forma geral, divergindo da realidade das aulas presenciais, nas quais cada aluno é atendido em sua especificidade, dessa forma a estratégia adotada passou a ser a elaboração de planos e aulas individualizadas. 


\section{Categoria 02: potencialidades}

Para além dos desafios narrados pelos professores, foi questionado ainda se conseguem encontrar algo positivo, alguma potencialidade nesse contexto. Dois dos participantes afirmam que sim e narram:

[...] Contato com os pais, contato com professores de imediato, envio de materiais, de vídeos, aproximou, como entramos na casa de cada criança, aproximou mais, [...] eu acho que aproximou. Estamos longe, mas estamos perto, a gente entrou um na casa do outro né? [...] (P1).

[...] Mostrou o quanto o nosso trabalho é primordial mesmo, o quanto a gente faz a diferença trabalhando em equipe, em conjunto [...] (P2).

Observa-se nas narrativas que as tecnologias por meio de contato embora virtual, trouxeram uma maior proximidade na relação família escola. Esse contato é de extrema importância uma vez que a escola e a família possuem um objetivo em comum, sendo o desenvolvimento integral do filho/aluno. Para Costa, Silva e Souza (2019), essa relação enriquece e facilita o desempenho educacional da criança, portanto, é necessário que a família assuma essa responsabilidade com a escola, para que o desenvolvimento da criança de fato seja alcançado. A família deve ser participativa na escola e a escola por sua vez, deve ser receptiva a família e permitir a troca de ideias, pontos de vistas, estudando meios para que isso seja possível, já que essa parceria pode resultar em um desenvolvimento e formação integral, abrangendo o desenvolvimento motor, psicológico, emocional, social e intelectual dos filhos-alunos.

Já para o participante P-3 "não houve” ponto positivo.

\section{Categoria 03: estratégias}

Quando indagados a cerca de qual ou quais estratégias foram adotadas por eles para atender aos alunos, algumas foram citadas, como elas se deram no decorrer de todo o encontro, optamos por listar as que foram narradas, como:

-Whatsapp - grupo com pais, grupo com professores e lista de transmissão.

- Wordwall-plataforma de quižes, competições, jogos de palavras e outros recursos que têm facilidade para ser adaptada aos alunos com deficiência.

- Stremyeard - um estúdio virtual que permite que os usuários façam lives com mais de uma pessoa ao mesmo tempo, deixa as lives mais profissionais, como a possibilidade de alterar o quadro de exibição dos convidados, criar banners com o título da transmissão e o compartilhamento de tela.

- Meet - serviço de comunicação por vídeo desenvolvido pelo Google. 
Observa-se que, estas não são tecnologias novas, mas as mesmas por um longo tempo foram tangenciadas do contexto escolar, agora apresentam-se como aliadas ao processo, é valido ressaltar que embora as tecnologias adotadas sigam o mesmo padrão, cada uma delas, foi utilizada de forma a atender a especificidade de cada criança, considerando às necessidades específicas. De acordo com as Diretrizes Curriculares Nacionais para a Educação Especial instituída em 2001, é necessário respeitar cada sujeito nas instituições de educação, buscando atender todas as crianças, elaborando estratégias, adequações e adaptações do currículo que viabilizem o avanço de sua aprendizagem.

\section{Categoria 04: desafios pessoais}

Para além, dos objetivos traçados para pesquisa, evidenciou-se nas narrativas que os desafios docentes não estão apenas relacionados as técnicas exigidas da profissão, mas também se referem aos desafios pessoais, uma vez que estes profissionais, atuavam de acordo com a carga horária de cada um em suas unidades, o que se tornou inviável pela pandemia, transpondo cada um para o trabalho em home office:

[...] Agora tem que se preocupar, onde deixar meu filho, ver se a internet está funcionando, adaptar toda a casa... Bom, vou falar um pouquinho da minha realidade para vocês entenderem. Eu moro bem no centro da cidade, em frente a dois hospitais, um adulto e um infantil, então, o barulho é desde $4 \mathrm{~h}$ da manhã até as $11 \mathrm{~h}$ da noite. Então, eu tenho que adaptar o som da minha casa, pois eu sei que tem crianças que precisam de atenção sem nenhum outro estímulo [...] (P1).

[...] É um turbilhão de coisas que vem de pais, da escola, dos professores, dos alunos, da comunidade e até da própria mídia que às vezes a gente vê lá uma notícia, que os professores não querem voltar porque querem ficar em casa, sem trabalhar e a gente fica um pouco triste com essas informações $[\cdots](\mathrm{P} 3)$.

[...] sou acostumada a trabalhar presencialmente. Não me acostumei dessa forma. Não suporto na verdade. Não gosto de trabalhar dessa forma. Não consegui [...] (P3).

É possível perceber a partir das narrativas a pressão psicológica que os professores estão enfrentando, fato que acarreta um desgaste ainda maior, considerando que no modelo em que atuavam anteriormente era possível de certa forma realizar uma separação entre a atuação docente em suas unidades escolares, mas em suas casas assumirem-se como pais, mães, filhos e assim por diante, estes repentinamente, se viram diante da necessidade de mudança de tempo e espaço, uma vez que a "escola entrou” em suas casas, e a separação por vezes já não é mais possível, gerando um acúmulo dos afazeres. 
Destaca-se ainda que falácias, como "professores não querem trabalhar" e outras nesse sentido, afetam intimamente a vida dos docentes, que se veem além da necessidade do cumprimento de suas atribuições, a necessidade de terem que provar publicamente que estão fazendo, um estudo realizado no presente ano pelo Instituto Península, intitulado: Sentimento e percepção dos professores brasileiros nos diferentes estágios do coronavírus no Brasil, aponta que:

[...] diante dessas mudanças e incertezas, associadas às restrições de mobilidade da população, as demandas e expectativas que recaem sobre as professoras e professores aumentaram ainda mais, trazendo junto com elas sentimentos como medo, ansiedade e insegurança. (INSTITUTO PENÍNSULA, 2020, p.24).

O estudo se comprova também nas narrativas dos professores participantes, percebe-se a preocupação e empenho em não deixar nenhuma criança sem atendimento, na busca por novas estratégias atrelado a inexperiência de atuação neste modelo e as cobranças externas recebidas.

\section{Considerações finais}

No início do ano de 2020 nos deparamos com o começo de uma situação pandêmica que resultou no fechamento das escolas como uma maneira de enfrentamento ao novo corona vírus, os educadores precisaram se reinventar para garantirem o atendimento educacional a todos os alunos, sem exceção. Desse modo, a presente pesquisa teve como objetivo investigar quais as estratégias estão sendo utilizadas pelos professores da educação inclusiva para garantir o atendimento educacional.

A partir dos dados coletados, foi possível notar que apesar dos esforços, os desafios ainda são significativos, uma vez que o contexto atual releva também o acúmulo de anos com baixo investimento em práticas que de fato considerem a diversidade, a necessidade de práticas não homogeneizadoras, o que intensifica os desafios para uma educação de fato inclusiva e eficaz, descortinou-se ainda a nítida falta de investimento no preparo dos professores para conhecimento e manuseio de tecnologias para fins educacionais.

Vale destacar também que, a partir das narrativas analisadas, foi possível notarmos alguns impactos positivos, bem como estreitamento da relação dos professores e famílias.

Sabendo dos desafios que estão sendo enfrentados na educação nesse momento, é importante salientar que por ser um momento novo, os estudos que abordam a educação em contexto de pandemia ainda são tímidos, contudo, há um número menor ainda que aborde o atendimento aos alunos com deficiência, nesse contexto. Assim, apontamos para necessidade de que mais pesquisas sejam realizadas abordando a temática inclusão educacional e deficiência. 
Ressalta-se ainda como a internet, o uso de aparelhos tecnológicos como o celular, por muito tempo foram vistos como vilões no contexto educacional, tendo por exemplo o uso deste último, sido inclusive proibido por determinações e regimes organizacionais, e este ano, todas essas concepções precisaram ser reavaliadas, uma vez que se tornaram aliados.

A educação a distância já era conhecida por todas as pessoas antes da pandemia, contudo, sendo uma modalidade optativa, que diante da nova realidade, no Brasil, esta e outros modelos similares se tornaram as únicas alternativas. Com a análise dos dados, foi evidenciado que apesar dos desafios, existem diversos elementos que potencializaram a aprendizagem das crianças com deficiência. Pesquisar sobre como os professores estão conseguindo atender as crianças com deficiência foi essencial para compreendermos o processo de apropriação de ferramentas tecnológicas que já existiam, mas até então não eram utilizadas, quando utilizadas ocorria timidamente e nem sempre para este fim e agora se destacaram como possibilidades de alcance e tentativa de garantia do acesso a educação aos alunos.

\section{Referências}

ALVES, Maria; PEREIRA, Guilherme; VIANA, Maria. Tecnologia assistiva na perspectiva de educação inclusiva: o ciberespaço como lócus de autonomia e autoria. Laplage em Revista, Sorocaba, v. 3, n. 2, p. 159-169, maio-ago, 2017.

BRASIL. Resolução CNE/CEB N N 2, de 11 de setembro de 2001. Institui Diretrizes Nacionais para a Educação Especial na Educação Básica. MEC: Brasília - DF, 2008.

BRASIL. Lei no 13.146, de julho de 2015. Institui a Lei Brasileira de Inclusão da Pessoa com Deficiência. Diário Oficial da União: seção 1, Brasília, DF, p.1-74, 077 de jul. 2015.

BRASIL. Constituição da República Federativa do Brasil: texto constitucional promulgado em 5 de outubro de 1988, com as alterações determinadas pelas Emendas Constitucionais de Revisão nos 1 a 6/94, pelas Emendas Constitucionais nos 1/92 a 91/2016 e pelo Decreto Legislativo no 186/2008. Secretaria de editoração e Publicações Coordenação de Edições Técnicas. Brasília, DF, 2016.

BRASIL. Lei n. 9.394, de 20 de dezembro de 1996. Estabelece as diretrizes e bases da educação nacional. Diário Oficial: seção 1, Brasília, DF, p. 1-289, dez. 1996.

COSTA, Maria; SILVA, Francisco; SOUZA, Davison. Parceria entre escola e família na formação integral da criança. Ver. Pemo, Fortaleza, v.1, n.1, p. 1-14, 2019. Disponível em: https://doi.org/10.47149/pemo.v1i1.3476 Acesso em: 03, jan, 2021.

GALVÃO-FILHO, T. A. A construção do conceito de Tecnologia Assistiva: alguns novos interrogantes e desafios. Revista da FACED - Entre ideias: Educação, Cultura e Sociedade, Bahia, v. 2, n. 1, p. 25-42, jan./jun. 2013. Disponível em: http://www.galvaofilho.net/TA_desafios.htm Acesso em: 04, jan. de 2021. 
GATTI, Bernadete. Grupo focal na pesquisa em Ciências Sociais e Humanas. Brasília: Líber Livro, 2005.

INSTITUTO PENÍNSULA. Pesquisa de sentimento e percep̧ão dos professores brasileiros nos diferentes estágios do Corona vírus no Brasil. Instituto Península: São Paulo, 2020.

HELIÓTERIO, Margarete; LOPES, Fernanada; SOUZA, Camila at al. Covid-19: por que a proteção da saúde dos trabalhadores e trabalhadoras da saúde é prioritária no combate à pandemia. SciElo Preprints, O preprint não foi submetido para publicação. 2020. Disponível em: https://doi.org/10.1590/SciELOPreprints.664 Acesso em: 2 de jun. 2020.

LEAL, Paulo SOUZA. A educação diante de um novo paradigma: ensino a distância (EAD) veio para ficar!. Revista Gestão \& Tecnologia, v. 1, n. 30, p. 41-43, jan/jun. 2020 Disponível em:

http://faculdadedelta.edu.br/revistas3/index.php/gt/article/view/44/40 Acesso em: 8 de out. 2020.

LOPES, Valéria; FREITAS, Carlos; FREITAS, Flaviane. Educação especial inclusiva e tecnologia social. Espacios, Venezuela, v. 38, n. 45, p. 6-24, 2017. Disponível em:

https://www.revistaespacios.com/a17v38n45/a17v38n45p06.pdf Acesso em: 10 de out. 2020.

MORAES, Roque; GALIAZZI, Maria. Análise Textual Discursiva. 2.ed. Ijuí: Unijuí, 2011.

MANTOAN, Maria; PRIETO, Rosângela. Inclusão Escolar: pontos e contrapontos. São Paulo: Summus, 2006.

MONTEIRO, Sandrelena da Silva. (Re) inventar educação escolar no Brasil em tempos da covid19. Revista Augustus, Rio de Janeiro, v. 25, n. 51, p. 237-254, 2020. Disponível em: https://doi.org/10.15202/1981896.2020v25n51p237 Acesso em: 30 de nov. 2020.

NUNES, Sylvia; SAIA, Ana; TAVARES, Rosana. Educação inclusiva: entre a história, os preconceitos, a escola e a família. Psicologia: ciência e profissão, Alfenas - MG, v. 35, n. 4, p. 11061119, 2015. Disponível em: https:// doi.org/10.1590/1982-3703001312014 Acesso em: 20, de set. 2020

ROSA, Rosane. Das aulas presenciais às aulas remotas: as abruptas mudanças impulsionadas na docência pela ação do Coronavírus - o COVID-19. Rev. Cient. Schola, Rio Grande do Sul, v. 6, n. 1, p. 4-6, jul. 2020. Disponível em: http://avaliacao.se.df.gov.br/wp-

content/uploads/2020/08/Rosa-2020-Das-aulas-presenciais-as-aulas-remotas_-as-abruptasmudancas-impulsionadas-na-docencia-pela-acao-do-Coronavirus-o-COVID-19.pdf Acesso em: 19 de jun. 2020

SANTOS, Bruna. Concepções de acadêmicos sobre a educação ambiental, ambientalização e sustentabilidade em uma instituição de educação superior. 2017. Dissertação (Mestrado em educação) - Universidade do Vale do Itajaí, Santa Catarina, 2017.

TAMAYO, Carolina; SILVA, Michela. Desafios e possibilidades para a Educação (Matemática) em tempos de "Covid-19" numa escola em crise. Revista Latinoamericana de Etnomatemática, v.13, n. 1, p. 29-48, 2020. 